\title{
Avaliação do desempenho, da produção de fezes e da digestibilidade de nutrientes em suínos de diferentes grupos genéticos ${ }^{1}$
}

\section{Performance evaluation, feces production and digestibility of nutrients in pigs from different genetic groups}

\author{
Caio Abércio da Silva ${ }^{2 *}$; Julian Cristina Borosky³; Ana Maria Bridi²; Marco \\ Antonio Rocha ${ }^{4}$; Roberta Abrami Monteiro Silva ${ }^{3}$; Graziela Drociunas Pacheco ${ }^{2}$
}

\begin{abstract}
Resumo
O objetivo deste trabalho foi avaliar o desempenho, a produção de fezes e a digestibilidade dos principais nutrientes da ração de suínos de diferentes genótipos. Foram utilizados 48 animais ( 24 machos castrados e 24 fêmeas), entre 50,81 $\pm 4,63 \mathrm{~kg}$ até $81,14 \pm 6,55 \mathrm{~kg}$ de peso vivo e idade média inicial de 93,63 \pm 6,08 dias, divididos em quatro tratamentos, representados por quatro genótipos: linhagem melhorada comercialmente, selecionada para crescimento e produção de carne magra; linhagem melhorada comercialmente, selecionada para fins de prolificidade; animais oriundos do cruzamento Landrace X Large White; e linhagem não melhorada geneticamente. Os animais foram alojados em número de 2 por baia e receberam rações isonutritivas e isonergéticas, além de água à vontade. O delineamento experimental utilizado foi inteiramente casualizado em arranjo fatorial $4 \times 2$ (linhagens genéticas; gêneros). Foi observado maior ganho diário de peso para os animais híbridos para carne em relação aos animais híbridos para prolificidade e melhor conversão alimentar para os animais híbridos para carne em relação aos demais grupos genéticos. A produção total de fezes (base matéria natural) foi menor $(\mathrm{P}<0,05)$ para os animais híbridos para carne em relação aos grupos híbridos para prolificidade e sem seleção. Os animais sem seleção apresentaram índices inferiores de digestibilidade para a matéria natural $(\mathrm{P}<0,05)$ e os animais dos grupos sem seleção e cruzados Large White $\mathrm{x}$ Landrace demonstraram o menor índice de digestibilidade para o fósforo. Suínos melhorados para produção de carne magra são mais eficientes na transformação de alimento em carne e apresentam menor produção fecal. Para o fator gênero as fêmeas são mais eficientes nos parâmetros de desempenho.
\end{abstract}

Palavras-chave: Dejetos, digestibilidade, método de coleta parcial

\begin{abstract}
The objective of this experiment was to evaluate the performance, feces production and digestibility of the main nutrients in feed of different pig genotypes. Forty eight pigs (24 barrows and 24 gilts) averaging $50.81 \pm 4.63 \mathrm{~kg}$ until $81.14 \pm 6.55 \mathrm{~kg}$ of body weight and $93.63 \pm 6.08$ days of age were used. Four treatments represented by four lineages were used: 1- commercial pig breeding line, selected for growth and lean meat production; 2- commercial pig breeding line, selected for prolificacy; 3- crossbred animals (Landrace x Large White); 4- non selected genetic line. Two animals were housed per pen and they received isonutrient and isoenergetic and feed and water ad libitum. The experimental design was completely randomized in a $4 \times 2$ factorial arrangement (genetic lines, genders). A greater average daily
\end{abstract}

\footnotetext{
1 Parte da dissertação de Mestrado em Ciência Animal, do primeiro autor, Universidade Estadual de Londrina, UEL, Londrina, PR.

${ }^{2}$ Profs. Drs. do Dept ${ }^{\mathrm{o}}$ de Zootecnia. Universidade Estadual de Londrina, UEL, Londrina, PR. E-mail: casilva@uel.br; ambridi@ uel.br; grazivetuel@yahoo.com.br

${ }^{3}$ Discente(s) de Mestrado em Ciência Animal, UEL, Londrina, PR. E-mail: juliancborosky@hotmail.com; ro_abrami@hotmail.com

${ }^{4}$ Prof. Dr. Aposentado do Dept ${ }^{\text {o }}$ de Zootecnia, UEL, Londrina, PR. E-mail: marocw@hotmail.com

* Autor para correspondência
} 
gain was observed to hybrid animals selected for lean meat production compared to animals selected to prolificacy and a greater feed conversion was observed for the hybrid animals for lean meat $(\mathrm{P}<0.05)$. Total feces production (natural matter basis) had a lower level $(\mathrm{P}<0.05)$ for the hybrid animals for lean meat production compared to the hybrid group for prolificacy and non-selected genetic group. The animals without selection showed lower digestibility indexes for natural matter $(\mathrm{P}<0.05)$ and the nonselected genetic group and crossbred animals (Large White $\mathrm{x}$ Landrace) showed the lowest digestibility index for phosphorous. Pigs select for growth and lean meat production are more efficient in converting food into meat and have less fecal production. According the gender, the females are more efficient to the performance parameters.

Key words: Dejection, digestibility, partial collection method

\section{Introdução}

A produção de suínos com alto rendimento de carne magra, de boa qualidade sensorial e industrial, e sob baixo custo corresponde aos principais objetivos do setor suinícola, determinando uma intensa seleção genética para índices de crescimento, desenvolvimento muscular e para um alto número de desmamados (HANENBERG; KNOL; MERKS, 2001; SILVA et al., 2003).

Este quadro tem consolidado a estruturação da suinocultura industrial com linhagens comerciais melhoradas de alta performance, embora ainda existam granjas que preservam animais puros ou cruzados, mas não necessariamente melhorados, e produtores que não investem no avanço genético, mantendo uma consanguinidade decorrente da retirada de matrizes de reposição do próprio plantel.

Esta diversidade de procedimentos tem resultado em índices de produção bastante distintos, com repercussões diretas nos parâmetros de desempenho, com grandes variações no aproveitamento dos nutrientes das rações e, por consequência, na produção de fezes e no perfil poluente dos dejetos.

A preocupação atual com a minimização da capacidade poluente gerada pela suinocultura é crescente. Muitos trabalhos apontam que a quantidade de fezes e a qualidade poluente desta são influenciadas pela quantidade, composição e forma física do alimento, pelo sexo, peso vivo, pelas atividades desenvolvidas, pela temperatura, umidade, pelo nível de fibra e proteína na ração, além do volume de água ingerida (CLANTON;
NICHOLS; MOSER, 1991; OLIVEIRA， 1994; BELLI FILHO, 1995), mas existem poucos trabalhos que relacionam a produção de fezes com a base genética dos animais.

Algumas tabelas de nutrição têm levado em consideração a relação das características genéticas com as exigências nutricionais (NRC, 1998; ROSTAGNO et al., 2011), mas há poucas referências que tratam deste fator com a produção de fezes.

O objetivo deste trabalho foi identificar os resultados dos diferentes genótipos suínos sobre o desempenho zootécnico, a produção de fezes e a digestibilidade dos principais nutrientes da ração.

\section{Material e Métodos}

O experimento foi conduzido no Setor de Suinocultura da Fazenda Escola da Universidade Estadual de Londrina. Foram utilizados 48 animais (24 machos castrados e 24 fêmeas), com peso médio inicial de 50,81 $\pm 4,63 \mathrm{~kg}(93,63 \pm 6,08$ dias de idade) até $81,14 \pm 6,55 \mathrm{~kg}$ de peso vivo, provenientes de quatro grupos genéticos, sendo: 1linhagem melhorada comercialmente, selecionada para crescimento e produção de carne magra; 2linhagem melhorada comercialmente, selecionada para fins de prolificidade; 3- animais oriundos do cruzamento de suínos Large White x Landrace; 4linhagem não melhorada geneticamente.

O delineamento experimental utilizado foi inteiramente casualizado em arranjo fatorial $4 \times 2$ 
(4 padrões genéticos e 2 sexos), onde cada baia representou uma repetição.

Os animais foram alojados em baias de alvenaria, com $3 \mathrm{~m}^{2}$ de área (2 animais do mesmo gênero por baia) e receberam rações isonutritivas e isoenergéticas, ad libitum, formuladas para atender às exigências mínimas recomendadas pelo NRC (1998) para a fase de Crescimento II (Tabela 1).

Tabela 1. Composição percentual e calculada da ração experimental utilizada na fase de crescimento $(50$ a $80 \mathrm{~kg}$ de peso vivo).

\begin{tabular}{lc}
\hline Ingredientes (\%) & Crescimento II \\
\hline Milho & 71,230 \\
Farelo Soja & 21,105 \\
Óleo & 3,107 \\
Núcleo & 4,000 \\
L-lisina & 0,246 \\
DL-metionina & 0,062 \\
Sal & 0,250 \\
\hline Total & 100 \\
\hline Valores calculados & \\
\hline Proteína Bruta (\%) & 18,80 \\
E. Metab. (kcal/kg) & 3162 \\
Fibra Bruta (\%) & 2,71 \\
Extrato etéreo (\%) & 2,77 \\
Cálcio (\%) $\%$ (\%) & 0,90 \\
Fósforo total (\%) & 0,65 \\
Lisina total (\%) & 0,98 \\
Metionina total (\%) & 0,30 \\
Treonina total (\%) & 0,74 \\
Metionina + cistina total (\%) & 0,61 \\
\hline
\end{tabular}

Níveis de garantia por kg de produto: 'Núcleo Suínos Recria SD: ácido fólico, 28,00 mg; ácido pantotênico, $280 \mathrm{mg}$; biotina, 1,50 mg; cálcio, 190 g; cobalto, 4,6 mg; cobre, $3412 \mathrm{mg}$; colina, 4,0 g; ferro, $2900 \mathrm{mg}$; flúor (máx), $595 \mathrm{mg}$; fósforo, $62 \mathrm{~g}$; iodo, 37,0 mg; manganês, $1200 \mathrm{mg}$; niacina, $554 \mathrm{mg}$; piridoxina, $50 \mathrm{mg}$; promotor de crescimento, $2000 \mathrm{mg}$; riboflavina, $112 \mathrm{mg}$; selênio, 9 mg; sódio, 54 g; tiamina, 28 mg; vit.A, 140000 UI; vit.B12, 700 mcg; vit.D3, 56000 UI; vit.E, 280 mg; vit.K3, 56 mg; zinco, 2750.

Fonte: Elaboração dos autores.

Para avaliação do desempenho (50 até $80 \mathrm{~kg}$ de peso vivo) foram utilizados os parâmetros ganho diário de peso, consumo diário de ração e conversão alimentar e tempo em dias para os animais atingirem $80 \mathrm{~kg}$ de peso vivo em média.

Para a determinação da digestibilidade da proteína bruta, da matéria seca, da fibra bruta e do fósforo das rações pelas diferentes genéticas, foi adotada a técnica da coleta parcial de fezes (OETTING, 2002), utilizando como marcador o óxido crômico a $0,3 \%$.
A análise da digestibilidade e a avaliação da produção de fezes foram iniciadas quando os animais estavam com $62,71 \pm 10,02 \mathrm{~kg}$ de peso vivo. Este peso foi considerado como um peso médio para a fase compreendida entre 50 e $80 \mathrm{~kg}$ de peso vivo. As rações marcadas foram oferecidas aos suínos durante cinco dias. Após dois dias de adaptação e manutenção do fluxo dos marcadores no trato gastrintestinal, foi realizada a coletas das fezes durante três dias de ambos os animais da baia. As amostras de fezes (em torno de $100 \mathrm{~g}$ ) 
foram coletadas diretamente do reto, duas vezes ao dia (manhã e a tarde) e armazenadas em freezer a $-4^{\circ} \mathrm{C}$. Posteriormente, as fezes foram secas a $60^{\circ} \mathrm{C}$ em estufa de ventilação forçada e analisadas por espectrofotometria de absorção atômica para a determinação do cromo, conforme metodologia de Kimura e Miller (1957). O mesmo procedimento foi desenvolvido para a determinação do cromo na ração. Os nutrientes avaliados (matéria seca, matéria mineral, proteína bruta e fósforo) foram determinados pelas metodologias descritas pela AOAC (1984).

O cálculo dos coeficientes de digestibilidade pela técnica da coleta parcial das fezes foi realizado de acordo com a equação proposta por Nose (1966):

$\mathrm{CD}(\%)=100-100 \times(\%$ marcador ração $) \times(\%$ nutrientes nas fezes $)$

(\% marcador fezes) x (\% nutrientes na ração)

Baseado nos resultados de digestibilidade da matéria seca e no consumo de ração durante o período experimental foi calculada a produção diária e total de fezes no período.

Os dados foram submetidos à análise de variância, utilizando-se o programa SAEG (UFV, 1997) e as médias foram comparadas utilizando-se o teste de Duncan a $5 \%$.

\section{Resultados e Discussão}

De acordo com os resultados de desempenho (Tabela 2), suínos híbridos melhorados para a produção de carne apresentaram maior ganho diário de peso $(\mathrm{P}<0,05)$ quando comparados a híbridos selecionados para prolificidade, não havendo, contudo, diferençaentreosdemaisgrupos.Alinhagem selecionada para carne apresentou melhor conversão alimentar $(\mathrm{P}<0,05)$ em relação às outras linhagens, indicando elevada eficiência de transformação. Também os animais de genótipo voltado para prolificidade demandaram mais tempo para atingir o mesmo peso final ( $80 \mathrm{~kg}$ em média) em relação aos demais grupos. Estes resultados indicam que os animais melhorados geneticamente apresentaram melhores características de desempenho e foram mais precoces. Os resultados obtidos se identificam com as observações de Bark et al. (1992), em que suínos de alta deposição de carne magra apresentam melhor conversão alimentar que suínos de baixa deposição de carne magra. Este quadro pode ser explicado pelo fato que em linhagens com alto ganho de carne magra foram observadas maiores concentrações de colecistoquinina plasmática, por unidade de alimento consumido, enquanto os níveis de glicose, insulina, IGF-I e hormônio de crescimento apresentaram-se maiores em relação a animais menos eficientes na deposição deste tecido magro (FORBES, 2007). Segundo Easter e Baker (1980) e Gu et al. (1991), as diferenças entre grupos genéticos estão associadas principalmente ao metabolismo de proteína e de energia.

Os suínos machos castrados apresentaram maior ganho diário de peso, maior consumo diário de ração e pior conversão alimentar $(\mathrm{P}<0,05)$. A menor transformação de alimento em carne dos machos castrados deve-se à maior deposição de tecido adiposo na carcaça (LARZUL et al., 1997). As diferenças entre os sexos foram semelhantes às observadas por Cisneros et al. (1996) e Hamilton et al.(2003). Em geral, suínos castrados cirurgicamente ou via imunização apresentam maior consumo de ração que animais inteiros ou fêmeas, o que pode ser atribuído aos menores níveis de andrógenos séricos (WEILER et al., 1996). Este excesso de consumo se traduz em mais ganho de peso e em maior deposição de tecido adiposo, cuja demanda por nutrientes é efetivamente maior, o que justifica a pior conversão em relação às fêmeas. 
Tabela 2. Médias para as características ganho diário de peso (GDP), consumo diário de ração (CDR) e conversão alimentar (CA) e tempo em dias para atingir $80 \mathrm{~kg}$ de peso vivo (D80) para as diferentes linhagens genéticas e gêneros.

\begin{tabular}{lcccc}
\hline Linhagens genéticas & GDP $(\mathrm{Kg})$ & CDR $(\mathrm{kg} /$ dia $)$ & CA & D 80 (dias) \\
\hline Híbrido carne & $1,12 \pm 0,13 \mathrm{a}$ & $2,46 \pm 0,20$ & $2,21 \pm 0,02 \mathrm{a}$ & $28,40 \pm 1,61 \mathrm{~b}$ \\
Híbrido prolificidade & $0,93 \pm 0,09 \mathrm{~b}$ & $2,43 \pm 0,32$ & $2,61 \pm 0,03 \mathrm{~b}$ & $32,09 \pm 2,95 \mathrm{a}$ \\
Landrace x Large White & $1,03 \pm 0,10 \mathrm{ab}$ & $2,75 \pm 0,43$ & $2,66 \pm 0,03 \mathrm{~b}$ & $29,21 \pm 2,76 \mathrm{~b}$ \\
Sem seleção & $1,02 \pm 0,06 \mathrm{ab}$ & $2,70 \pm 0,45$ & $2,64 \pm 0,10 \mathrm{~b}$ & $29,59 \pm 1,68 \mathrm{~b}$ \\
\hline Gêneros & & & & \\
\hline Machos & $1,08 \pm 0,12 \mathrm{a}$ & $2,82 \pm 0,30 \mathrm{a}$ & $2,62 \pm 0,31 \mathrm{~b}$ & $28,61 \pm 2,34 \mathrm{~b}$ \\
Fêmeas & $0,96 \pm 0,72 \mathrm{~b}$ & $2,35 \pm 0,27 \mathrm{~b}$ & $2,43 \pm 0,22 \mathrm{a}$ & $30,97 \pm 2,23 \mathrm{a}$ \\
\hline C.V. $(\%)$ & 7,10 & 10,07 & 7,81 & 6,12 \\
\hline
\end{tabular}

Médias seguidas de letras distintas na mesma coluna indicam diferença $(\mathrm{P}<0,05)$.

Fonte: Elaboração dos autores.

Quanto à produção total e diária de fezes dos diferentes grupos genéticos e gêneros foram observadas diferenças $(\mathrm{P}<0,05)$ para a primeira característica(Tabela3), ondeosanimaisprovenientes de programas comerciais de melhoramento genético para desempenho e produção de carne (híbridos carne) apresentaram menor produção total de fezes no período avaliado, comparados com os animais híbridos para prolificidade. Contudo, não foi observada diferença destes grupos com os animais provenientes de cruzamentos entre Large White $\mathrm{x}$ Landrace e sem seleção. Animais selecionados para carne apresentaram consumo de ração semelhante ao grupo genético selecionado para prolificidade, porém tiveram maior ganho diário de peso e melhor conversão alimentar $(\mathrm{P}<0,05)$, o que reverte em menor produção de fezes. Para a produção diária de fezes com base na matéria seca, não foi observada diferença entre os grupos genéticos.

Tabela 3. Médias para as características de produção total de fezes com base na matéria natural (PFMN) e produção diária de fezes com base na matéria seca (PFMS) das diferentes linhagens genéticas e gêneros.

\begin{tabular}{lcc}
\hline Linhagens genéticas & PFMN $(\mathrm{kg})$ & PFMS $(\mathrm{kg})$ \\
\hline Híbrido carne & $9,55 \pm 1,11 \mathrm{a}$ & $0,34 \pm 0,04$ \\
Híbrido prolificidade & $13,63 \pm 1,47 \mathrm{~b}$ & $0,38 \pm 0,04$ \\
Landrace x Large White & $12,72 \pm 1,84 \mathrm{ab}$ & $0,38 \pm 0,06$ \\
Sem seleção & $12,83 \pm 3,49 \mathrm{ab}$ & $0,45 \pm 0,13$ \\
\hline Gêneros & & \\
\hline Machos & $11,98 \pm 2,93$ & $0,37 \pm 0,04$ \\
Fêmeas & $12,48 \pm 2,31$ & $0,41 \pm 0,04$ \\
\hline Coeficiente de variação (\%) & 18,92 & 19,98 \\
\hline
\end{tabular}

Médias seguidas de letras distintas na mesma coluna indicam diferença $(\mathrm{P}<0,05)$.

Fonte: Elaboração dos autores. 
Para o parâmetro digestibilidade não foi observada diferença estatística entre as linhagens para os índices de digestibilidade da proteína e da matéria mineral (Tabela 4). Entretanto, os resultados indicam que animais sem seleção apresentaram o pior índice de digestibilidade para matéria seca $(\mathrm{P}<0,05)$. Para a digestibilidade do fósforo o grupo sem seleção também apresentou resultados inferiores aos demais $(\mathrm{P}<0,05)$, sendo que os animais do grupo melhorado para carne demonstraram melhor $(\mathrm{P}<0,05)$ aproveitamento do fósforo em relação ao grupo Large White $\mathrm{x}$ Landrace, mas não diferiram dos animais híbridos selecionados para prolificidade (Tabela 4).

Tabela 4. Digestibilidade da matéria seca (DMS), do fósforo (DP), da proteína bruta (DPB) e da matéria mineral (DMM) de acordo com os grupos genéticos e gêneros.

\begin{tabular}{lclll}
\hline Linhagens genéticas & DMS \% & \multicolumn{1}{c}{ DP $\%$} & \multicolumn{1}{c}{ DPB \% } & DMM \% \\
\hline Híbrido carne & $82,14 \pm 1,17 \mathrm{a}$ & $58,06 \pm 3,79 \mathrm{a}$ & $88,78 \pm 3,67$ & $45,77 \pm 7,14$ \\
Híbrido prolificidade & $81,16 \pm 1,25 \mathrm{a}$ & $52,51 \pm 4,76 \mathrm{ab}$ & $84,52 \pm 4,26$ & $47,84 \pm 10,01$ \\
Landrace x Large White & $81,65 \pm 0,67 \mathrm{a}$ & $47,53 \pm 2,08 \mathrm{~b}$ & $83,84 \pm 2,69$ & $45,19 \pm 7,17$ \\
Sem seleção & $78,13 \pm 1,83 \mathrm{~b}$ & $38,43 \pm 2,65 \mathrm{c}$ & $84,59 \pm 9,13$ & $45,48 \pm 8,82$ \\
\hline Macho & $80,09 \pm 2,46$ & $44,20 \pm 7,93$ & $88,27 \pm 4,63$ & $46,08 \pm 7,36$ \\
Fêmea & $80,87 \pm 1,96$ & $50,14 \pm 8,13$ & $83,81 \pm 5,73$ & $45,77 \pm 7,96$ \\
\hline C.V. (\%) & 1,90 & 7,63 & 4,61 & 18,57 \\
\hline
\end{tabular}

Médias seguidas de letras distintas na mesma coluna indicam diferença $(\mathrm{P}<0,05)$.

Fonte: Elaboração dos autores.

Quanto ao gênero não foi observada diferença entre machos e fêmeas para todos os parâmetros analisados e também não se verificou interação entre os fatores (Tabela 4).

As diferenças de digestibilidade observadas entre grupos genéticos distintos identificam-se as afirmações de Qin et al. (2002), que atribuem que a capacidade digestiva entre estas populações, principalmente na estrutura do intestino grosso e, portanto, na habilidade da digestão da fibra dietética, é determinante para o parâmetro. Os autores relatam também que as variações entre grupos genéticos para estes índices são maiores entre animais melhorados e não melhorados. Ndindana et al. (2002), avaliando a digestibilidade de rações com alta fibra em suínos nativos (Mukota pigs) e em animais Large White, verificaram melhores índices de digestibilidade para os animais nativos, sendo o resultado provavelmente atribuído à maior capacidade proporcional do intestino grosso. Entretanto, Rizzi et al. (2007), trabalhando com animais provenientes de cruzamentos entre Large White X Landrace e uma raça local da Itália, verificaram piores valores de digestibilidade para os animais nativos.

\section{Conclusão}

A seleção e o melhoramento genético são instrumentos efetivos para a promoção do desempenho e da eficiência alimentar dos suínos e identificam-se como recursos para a redução quantitativa da condição poluente de suas fezes. Suínos melhorados para produção de carne magra mostraram ser superiores na transformação de alimento em carne, apresentaram melhores índices de digestibilidade e determinaram menor produção fecal. 


\section{Referências}

ASSOCIATION OF OFFICIAL ANALYTICAL CHEMISTS - AOAC. Official methods of analysis. 14. ed. Washington: AOAC, 1984. 1141 p.

BARK, L. J.; STAHLY, T. S.; CROMWELL, G. L.; MIYAT, J. Influence of genetic capacity for lean tissue growth on rate and efficiency of tissue accretion in pigs fed ractopamine. Journal of Animal Science, Madison, v. 70, n. 11, p. 3391-3400, 1992.

BELLI FILHO, P. Stockage et odeurs des dejections animales cas du lisier de porc. 1995. Thése (Docteur) École Nationale Supériore de Chimie, Rennes, France.

CISNEROS, F.; ELLIS, M.; MCKEITH, F. K.; MCCAW, J.; FERNANDO, R. L. Influence of slaughter weight on growth and carcass characteristics, commercial cutting and curing yields, and meat quality of barrows and gilts from two genotypes. Journal of Animal Science, Madison, v. 74, n. 5, p. 925-933, 1996.

CLANTON, C. J.; NICHOLS, D. A.; MOSER, R. L. Swine manure characterization as affected by environmental temperature, dietary level intake, and dietary fat addition. Transactions of the American Society of Agricultural Engineers, v. 34, n. 5, p. 2164-2170, 1991.

EASTER, R. A.; BAKER, D. H. Lysine and protein level in corn-soybean meal diets for growing- finishing swine. Journal of Animal Science, Madison, v. 50, n. 3, p. 467471, 1980.

FORBES, J. M. Growth and fattening. In: Voluntary food intake and diet selection in farm animals. Wallingford: CABI International, 2007, p. 310-340.

GU, Y.; SCHINCKEL, A. P.; FORREST, J. C.; KUEI, C. H.; WATKINS, L. E. Effects of ractopamine, genotype, and growth phase on finishing performance and carcass value in swine: I. Growth performance and carcass merit. Journal of Animal Science, Madison, v. 69, n. 7, p. 26852693, 1991.

HAMILTON, D. N.; ELLIS, M.; WOLTER, B. F.; SCHINCKEL, A. P.; WILSON, E. R. The growth performance of the progeny of two swine sire lines reared under different floor space allowances. Journal of Animal Science, Madison, v. 81, n. 5, p. 1126-1135, 2003.

HANENBERG, E. H. A. T.; KNOL, E. F.; MERKS, J. W. M. Estimates of genetic parameters for reproduction traits at different parities in dutch Landrace pigs. Livestock Production Science, v. 69, n. 2, p. 179-186, 2001.

KIMURA, F. T.; MILLER, V. L. Chromic Oxide Measurement, improved determination of chromic oxide in cow feed and feces. Journal of Agricultural and Food Chemistry, Washington, v. 5, n. 3, p. 216, 1957.
LARZUL, C.; LEFAUCHEUR, L.; ECOLAN, P.; GOGUE, J.; TALMANT, A.; SELLIER, P.; LE ROY, P.; MONIN, G. Phenotypic and genetic parameter for Longissimus muscle fiber characteristics in relation to growth, carcass and meat quality in Large White pigs. Journal of Animal Science, Madison, v. 75, p. 31263137, 1997.

NDINDANA, W.; DZAMA, K.; NDIWENI, P. N. B.; MASWAURE, S. M.; CHIMONYO, M. Digestibility of high fiber diets and performance of growing zimbabwean indigenous mukota pigs and exotic large white pigs fed maize based diets with graded levels of maize cobs. Animal Feed Science and Technology, Amsterdam, v. 97, n. 3-4, p. 199-208, 2002.

NOSE, T. Recent advances in the study of fish digestion in Japan. In: SIMPOSIUM ON FISH NUTRITION AND FISH FEED TECHNOLOGY, 1966, Belgrade. Proceedings... Belgrade: EIFAC/FAO, 1966. CD-ROM.

NUTRIENT REQUERIMENT OF SWINE - NRC. National academic of sciences. 10. ed. Washington: NRC, 1998.

OETTING, L. L. Avaliação de diferentes marcadores para a determinação da digestibilidade e taxa de passagens do alimento em suíno. 2002. Dissertação (Mestrado em Ciências) - Centro de Energia Nuclear na Agricultura, Universidade de São Paulo, Piracicaba.

OLIVEIRA, P. A. Manejo da água e detalhes construtivos - influência no volume de dejetos produzidos. In: DIA DE CAMPO SOBRE MANEJO E UTILIZAÇÃO DE DEJETOS, 1994, Concórdia. Anais... Concórdia: EMBRAPA-CNPSA, 1994. p. 25-28.

QIN, G. X.; XU, L. M.; JIANG, H. L.; VAN DER POEL, A .F. B.; BOSCH, M. W.; VERSTEGEN, M. W. A. The effects of Chinese and Argentine soybeans on nutrient digestibility and organ morphology in Landrace and Chinese Min pigs. Asian-Australasian Journal of Animal Science, v. 15, p. 555-564, 2002.

RIZZI, L.; MARTELLI, G.; PAGANELLI, R.; SIMIOLI, M.; SARDI, L. Digestibility and nitrogen balance of diets containing non conventional vegetable proteins fed to pigs of genetic strains suitable for outdoor systems. Italian Journal of Animal Science, Madison, v. 6, n. 1, p. 353-355, 2007.

ROSTAGNO, H. S.; ALBINO, L. F. T.; DONZELE, J. L.; GOMES, P. C.; OLIVEIRA, R. F.; LOPES, D. C.; FERREIRA, A. S.; BARR, S. L. T. Tabelas brasileiras para aves e suinos: composição de alimentos e exigências nutricionais. Viçosa, MG: UFV, 2011. 252 p. 
SILVA, M. V.; LOPES, P. S.; GUIMARÃES, S. E.; WEILER, U.; ClAUS, R.; DEHNHARD, M.; TORRES, R. A. Utilização de marcadores genéticos em HOFÄCKER, S. Influence of the photoperiod and a light suínos. II. Características de desempenho e de qualidade da carne. Archivos Latinoamericanos de Producción Animal, Mayaguez, Porto Rico, v. 11, n. 1, p. 11-20, 2003.

UNIVERSIDADE FEDERAL DE VIÇOSA - UFV. reverse program on metabolically active hormones and food intake in domestic pigs compared with a wild boar. Canadian Journal of Animal Science, Sherbrooke, v. 76, p. 531-539, 1996.

Sistema de análises estatísticas e genéticas - SAEG. Versão 7.1. Viçosa, MG, 1997. 150 p. 